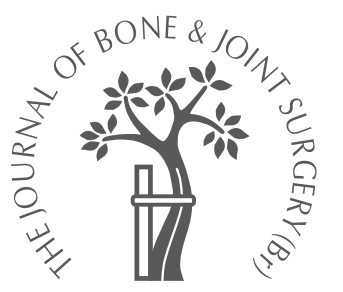

M. Firl,

L. Wünsch

From the Medical

University Lübeck,

Lübeck, Germany

\title{
Measurement of bowing of the radius
}

Fractures and plastic deformities of the forearm are common in children. While axial deformities are easily recognised and treated, bowing of the radius may be overlooked. Physiological bowing is essential for full rotation of the forearm. We have used the method of Schemitsch and Richards to estimate the degree of bowing in $\mathbf{1 0 0}$ children who had not suffered a fracture of the forearm.

The site of maximum bowing remained constant at $60.39 \%$ of the length of the radius (95\% Cl 59.65 to 61.14$)$. The value of maximum bowing did not exceed $10 \%$ of the total length (mean value $7.21 \% ; 95 \% \mathrm{Cl} 7.00$ to 7.41 ). This study provides information that can be useful for the diagnosis of bowing and for the evaluation of post-traumatic deformities.

Bowing of the radius is of crucial importance to the normal range of rotation of the forearm and to the strength generated by the muscles. ${ }^{1}$ Alteration of the normal bowing may result from fractures of the radius and from plastic deformation, a typical injury of childhood. $^{2,3}$ While axial deformities of the forearm are easily recognised, changes of bowing may be subtle, and minor fractures which may influence it, are frequently missed. ${ }^{4} \mathrm{~A}$ method of measuring bowing in children and the normal values for different age groups would be of interest. The kinematics of pronation and supination are complex, but a simple method of assessment has shown good correlation with clinical parameters in adults. In 1992, Schemitsch and Richards ${ }^{5}$ described a method based on the measurement of three basic distances of the radius on the anteroposterior (AP) radiograph. Radial bowing was characterised by a maximum distance and site referred to as the total radial length. We investigated whether this method could be adopted for children. We studied children who had not sustained a fracture of the forearm and compared the results with those of one patient with an appropriate fracture who had reduced rotation and delay in union of the fracture of the ulna. We found that a slight modification of the method of Schemitsch and Richards ${ }^{5}$ is useful for the diagnosis of fractures causing bowing and for the evaluation of post-traumatic deformities in children.

\section{Patients and Methods}

Bowing of the radius was measured in 100 children aged from one to 15 years using the method of Schemitsch and Richards. ${ }^{5}$ A retrospective study was conducted on clinical charts and radiographs from children who had been seen for suspected injury to the forearm. Their parents gave written consent to scientific evaluation of the data obtained from diagnostic and therapeutic studies. For inclusion in the survey we required standardised AP and lateral radiographs of the forearm, including the wrist and elbow and with identification of the bicipital tuberosity. In order to exclude evidence of fracture or bowing the radiographs were assessed by two independent observers experienced in paediatric trauma and blinded to the scope of the study. Children were excluded if they had persistent pain or limitation of movement in the forearm, if the observers disagreed or if the radiographs were inadequate. During follow-up no patients showed clinical evidence of a fracture and all had full rotation of the forearm and a normal grip.

Radial bowing is best measured on standardised projections taken in neutral rotation. On an AP radiograph of the forearm, the length of the radius (y), the location of maximum radial bow and the maximal distance of the radius from this point is measured. The distance (y) is measured from the bicipital tuberosity to the distal radioulnar joint. As most of our patients had incomplete ossification the distal radial epiphysis was used as the refer- 

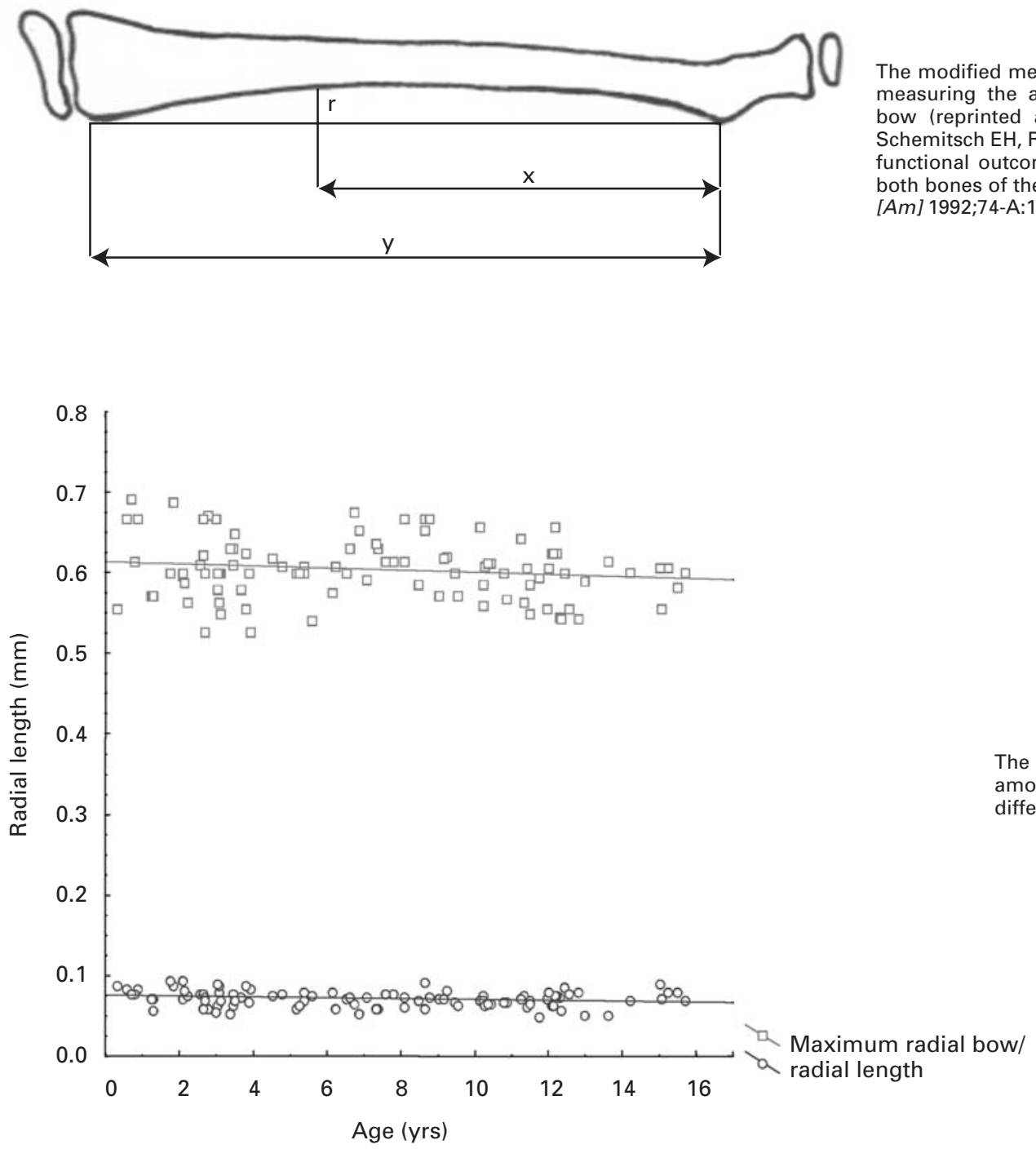

Fig. 1

The modified method of Schemitsch and Richards ${ }^{5}$ for measuring the amount and site of maximum radial bow (reprinted and modified with permission from Schemitsch EH, Richards RR. The effect of malunion on functional outcome after plate fixation of fractures of both bones of the forearm in adults. $J$ Bone Joint Surg [Am] 1992;74-A:1068-78.)
Fig. 2

distribution of values for site and Theunt of maximum radial bowing for ifferent ages in the population. ence point. This modified method of Schemitsch and Richards ${ }^{1}$ is shown in Figure 1. At the point of maximum radial bow, a perpendicular line $(\mathrm{r})$ is drawn to $(\mathrm{y})$ and the distance is measured. This value indicates the maximum radial bow. To determine the site of maximum radial bow, the distance from the bicipital tuberosity to the point of maximum bow is divided by the length of the entire bow and expressed as percentage (x/y x 100). By applying this method, bones of different length can be compared. Due to the highly variable bone length in our patients, the maximum radial bow $(r)$ was also reported as a percentage of the radial length (y), calculating r/y x 100. Data were evaluated using the statistics program STATISTICA (Statsoft Inc, Tulsa, Oklahoma).

\section{Results}

The distribution of values for the site of maximum bowing is shown in Figure 2. The mean value was $60.39 \%$ (SD \pm $3.74 \% ; 95 \%$ CI 59.65 to 61.14$)$. The mean value of maxi- mum radial bow was $7.21 \%$ of the total radial length $(\mathrm{SD} \pm$ $1.03 \% ; 95 \%$ CI 7.00 to 7.41$)$. While the length of the radius and the maximum bowing increased with age, the site of maximum radial bowing ( $\mathrm{x} / \mathrm{y} \mathrm{x} 100)$ remained constant.

Clinical application. A 13-year-old boy sustained an injury to the forearm after a fall. On the initial radiographs an undisplaced fracture of the ulna was diagnosed and fracture or subluxation of the radius excluded. A long-arm cast was applied for three weeks. After six weeks pronation was to $70^{\circ}$ and supination to $50^{\circ}$. Healing was delayed and progressive displacement of the fracture of the ulna became evident (Fig. 3). Analysis of radial bowing revealed a maximum bow ( $\mathrm{r}$ ) of $18 \mathrm{~mm}$, a radial length (y) of $170 \mathrm{~mm}$ and a site of maximum radial bow at $100 \mathrm{~mm}$. Expressed as percentage this showed the site of maximum bowing as $58.82 \%$, which was $10.59 \%$ of the radial length. These values are outside the normal figures outlined above and indicate the presence of a fracture of the radius. 


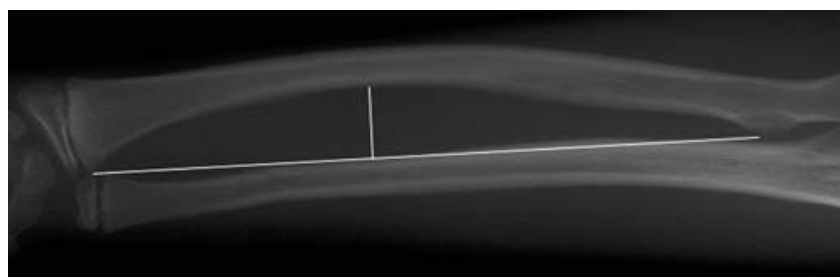

Fig. 3a

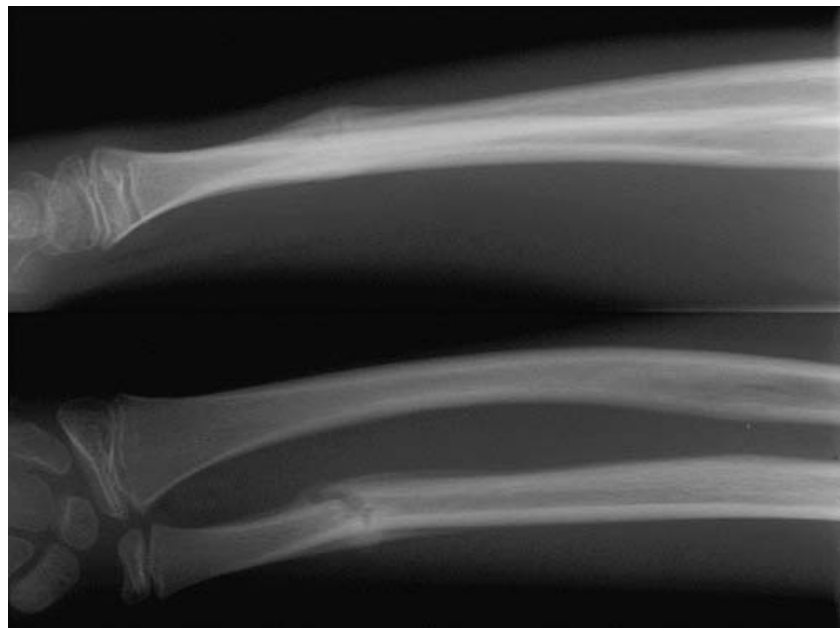

Fig. 3b

Radiographs of a 13-year-old boy. Figure $3 a-A$ fracture of the ulna was diagnosed, but the bowing fracture of the radius was missed. The maximum radial bow is $10.59 \%$ of radial length. Applying the modified method of Schemitsch and Richards ${ }^{5}$ at diagnosis, the bowing fracture of the radius would have been recognised $(r=18 \mathrm{~mm}, y=170 \mathrm{~mm}, x=100 \mathrm{~mm}$ ) Figure $3 b$ - Six weeks later, delayed consolidation and displacement of the ulna is evident. Supination was limited to $50^{\circ}$.

\section{Discussion}

The method of Schemitsch and Richards ${ }^{5}$ allows a quantitative description of radial bowing in the AP plane in children. Radial length (y) and the maximum radial bow $(r)$ clearly increase with age which, however, does not influence the site of maximum bowing. The median site of maximum radial bow in our group was $60.39 \%(\mathrm{SD} \pm 3.74 \%)$ and a similar value of $59.9 \%$; $(\mathrm{SD} \pm 0.7 \%)$ was observed by Schemitsch and Richards. ${ }^{5}$ They compared the radial bowing of plated forearm fractures to that of the uninvolved forearm. They described the normal values in adults and observed that better results were found after plating if the degree of bowing approached normal.

Measurement of radial bowing in children has both diagnostic and therapeutic implications. Measurement in one plane, although representing a simplification, gives clinically useful information. While bowing may be appreciated on the lateral view of the forearm without difficulty it may not be seen as easily on the AP view. The kinematics of the forearm are complex and their study requires sophisticated techniques using dynamic computerised tomography, magnetic resonance scans and complex mathematical models. ${ }^{6}$
These techniques make important contributions to basic research, but cannot be easily applied to injured children.

Good clinical results can be obtained in most children with conservative treatment, but remodelling of deformities of the middle-third of the forearm may be insufficient, and intramedullary nailing is becoming increasingly popular in the management of fractures in children. ${ }^{7-9}$

The importance of reconstructing the normal 'aspect' of the radius is stressed by various authors. ${ }^{10,11}$ Our results suggest that the site of maximum radial bow is at $60 \%$ of the radial length and that the maximum bowing should be below $10 \%$ of the radial length.

Our children presented with injuries to the forearm and had a radiological examination because of suspected fractures. They do not represent a truly normal population. Some patients might have had unrecognised bowing fractures. In these patients measurements of the radial bow eventually resulted in higher than normal values. Small differences in the AP projection of the forearm, however, may result in lower values. Measurement of the radial length (y) in younger children may have also been inaccurate because of incomplete ossification and difficulty in identifying the bicipital tuberosity.

In spite of this, our results were similar in all age groups and identical to those seen in adults. Measurement of bowing in children is of help in diagnosing bowing fractures and allows more detailed estimation of the process of diaphyseal remodelling. Our modification of the method of Schemitsch and Richards ${ }^{5}$ allows for estimation of the shape of the radius based on its length, which is independent of age. This may be useful clinically because it is based on standard radiographs.

No benefits in any form have been received or will be received from any commercial party related directly or indirectly to the subject of this article.

\section{References}

1. Richards RR. Chronic disorders of the forearm. J Bone Joint Surg [Am] 1996;78-A: 916-30.

2. Borden S. Traumatic bowing of the forearm in children. J Bone Joint Surg [Am]1974 56-A:611-6.

3. Borden S 4th. Roentgen recognition of acute plastic bowing of the forearm in children: a frequently missed injury. Am J Roentgenol 1975;125:524-30.

4. Crowe JE, Swischuk LE. Acute bowing fractures of the forearm in children. AJR Am J Roentgeno/ 1977;128:981-4.

5. Schemitsch EH, Richards RR. The effect of malunion on functional outcome after plate fixation of fractures of both bones of the forearm in adults. J Bone Joint Surg [Am] 1992;74-A:1068-78.

6. Weinberg AM, Pietsch IT, Krefft M, et al. Pronation and supination of the forearm: with special reference to the humero-ulnar articulation. Unfallchirurg 2001;104: 404-9.

7. Von Laer L. Frakturen und luxationen im wachstumsalter. Stuttgart Georg Thieme Verlag 1996:191-223.

8. Kuderna H. Connection between deviated axis and impaired function after fractures of the forearm. Unfallchirurgie 1980:7-13.

9. Dietz HG, Schmittenbecher PP, Illing P. Intramedulläre osteosynthese im wachstumsalter. Munich: Verlag 1997:105-34.

10. Müller FW, Link W, Wölfel R. Die intramedulläre Bündelnagelung bei kindlichen unterarmschaftbrüchen. In: Hoffmann S, v.Kap-herr, eds. Die Frakturen an Unterarm and Hand im Kindesalter. Universum Verlag Wiesbaden 1995:141-9.

11. Schärli AF. Operative therapie diaphysärer unterarmfrakturen. In: Hoffmann S, Kapherr eds. Die Frakturen an Unterarm und Hand im Kindesalter. Universum Verlag Wiesbaden 1995:128-31. 